This is the final peer-reviewed accepted manuscript of:

Guizzardi A, Stacchini A. Destinations strategic groups via Multivariate

Competition-based IPA. Tour Manag. 2017;58:40-50.

doi:10.1016/j.tourman.2016.10.004

The final published version is available online at:

https://doi.org/10.1016/j.tourman.2016.10.004

Rights / License:

The terms and conditions for the reuse of this version of the manuscript are specified in the publishing policy. For all terms of use and more information see the publisher's website.

This item was downloaded from IRIS Università di Bologna (https://cris.unibo.it/)

When citing, please refer to the published version. 


\title{
Destinations strategic groups via Multivariate Competition-based IPA
}

\author{
Guizzardi, Andrea*, Stacchini, Annalisa* \\ ${ }^{*}$ Department of Statistical Science and Centre for Advanced Studies in Tourism - CAST - \\ University of Bologna. Italy
}

\author{
Accepted on Tourism Management, 58, 40-50 (2017)
}

\section{Highlights}

1. We propose a Multivariate Competition-based IPA (MCIPA), for simultaneously comparing many destinations and detailing attributes prioritization in each.

2. The conceptual framework of strategic groups is the interpretative key of MCIPA, making multiple comparisons of importance-performance feasible and synthetic.

3. Combinations of importance values are interpreted in terms of target segment's preferences.

4. MCIPA provides strategic information to managers and policy makers, through a synthetic representation, accounting for the geographical and administrative context.

\begin{abstract}
This paper aims at developing a sound methodology for both extending Importance-Performance Analysis (IPA) to the consideration of many tourism destinations simultaneously, and defining the prioritization of core attributes for each. Multivariate Competition-based IPA (MCIPA) allow to provide detailed information of particular utility for destination management, through a synthetic representation, accounting also for the geographical and administrative context.

The conceptual framework of strategic groups, applied for the first time tourist destinations, is the interpretative key of MCIPA. It makes the comparison of importance and performance of various attributes in many areas feasible and synthetic. It lead to interpret combinations of importance values in terms of target segment's preferences, defining destinations with similar performances on the same target segment as direct rivals.

Based on a set of very broadly applicable statistical techniques, MCIPA helps addressing some methodological and interpretative drawbacks of IPA.. An application to Italian provinces is shown.
\end{abstract}

KEYWORDS: destinations competitiveness; strategic groups; multivariate clustering. 


\section{Introduction}

The knowledge of the strengths and weaknesses of the local supply brings an important informative contribution to managers and policy makers. In fact, effective tourism development strategies and policies should pursue efficient employment of resources. This requires profiling individual positioning, taking into account the importance and performance of various destination's aspects. Moreover, measuring competitiveness, especially with reference to tourist destinations, implies the detection and consideration of many competitors. The research question addressed in the present work is how to accomplish both task simultaneously through a sound methodology, providing a both extensive and itemized picture of the competitive scenario.

Our methodological proposal extends Competitive Importance-Performance Analysis (CIPA: Taplin, 2012b) through a multivariate methodology, able to provide detailed information about many destinations simultaneously, without giving up a synthetic and unified representation. Therefore, we propound a Multivariate Competition-based IPA (MCIPA), (re)proposing, in the tourism field, the conceptual framework of strategic groups, conceived in the context of corporate strategic management and, to the best of our knowledge, never applied before to tourist destinations. Accordingly, we hypothesize that combinations of importance values can be read in terms of target segment's preferences.

Thanks to the use of consolidated multivariate statistical methods and a competitionoriented interpretative underpinning, our proposal keeps the ease of reading and synthesis of traditional IPA. Meanwhile, it helps overcoming some IPA shortcomings, highlighted by the recent literature, especially about tourism (Sever, 2015; Arbore \& Busacca, 2011).

The way MCIPA allow to attain the aim described above can be resumed in 4 phases:

1) deriving importance measures, from satisfaction assessments, for each destination through a very flexible statistical methodology (properly conceived for ordinal data);

2) estimating "objective" performances for each tourism aspect, considering that each respondent (traveler) shall be conditioned by a wide set of variables (subjective, trip-related and socio-economic).

3) detecting strategic groups through a very flexible non-hierarchical clustering algorithm;

4) characterizing each group through priority-based attributes classification, reported in a caption where each destination attributes' prioritization is equal to those of the other members of the same group and shown in the corresponding column.

The thresholds used for the priority-based classification are data-centered but competition-based, as the importance-performance levels of each strategic group, for each tourism asset, is compared between groups instead of between attributes of only one (or pairs of) destination at a time. This method exploits a set of statistical techniques not often used in the tourism literature, but suitable in any case, not requiring restrictive distributional assumptions to hold, contrarily to widely used SEM, correlation analysis and linear regression. In this respect, MCIPA represents an innovation not only in the management practice, but also in the methodological field. In fact it takes into account destinations' geographical placement - a fundamental asset of the tourism supply (Assaf 
\& Josiassen, 2012) - and administrative context, influencing the formulation of development policies. Moreover thanks to this methodology both importance and performance measures are estimated the same way, expressed on the same scale and their meaning is directly implied by the models. However, the stepwise structure of MCIPA makes it very flexible and also partially applicable to many different empirical settings. For example, researchers preferring to use directly stated importance and performance can skip the first two steps.

Considering many destinations simultaneously, while retaining the information about the importance-performance relations within each location, is expected to improve the IPA methods, in extant literature. In particular: the discrepancies between conceptual interpretation and actual measurement of importance and performance, the arbitrariness of the IPA-positioning of averageperforming average-important aspects, and the excessive dimensional reduction of relevant information.

- For illustrative purposes, we show results of applying MCIPA to 100 Italian destinations. A sample of 1,429,230 questionnaires, covering 13 years, is retrieved from the survey on international tourism, published by the Central Bank of Italy (2014). So we also bring evidence about the competitive scenario of Italian provinces.

The paper is structured as follows. Section 2 describes the open issues highlighted by the literature. Section 3 presents the interpretative framework, centered on strategic groups, and limitations. Section 4 explains MCIPA methodology. Section 5 shows an application to the Italian case. Section 6 summarizes and concludes.

\section{Theoretical background and literature review}

\subsection{Analyzing destination competitiveness}

The tourism literature defines competitiveness as the capability of a destination to outperform rival locations in sustainably and efficiently attracting visitors (Ritchie \& Crouch, 2003). Competitiveness can be measured, from both the supply and the demand side, through either 'hard data', as the number tourist arrivals, overnight stays, tourist receipts (e.g. Assaf \& Josiassen, 2012), or 'soft data' about tourists motivations, satisfaction, intention to return (e.g. Cracolici \& Nijkamp, 2009), or both, often constructing composite indicators (e.g. Dwyer \& Kim, 2003). Crouch (2010) pointed out some difficulties concerning the use of quantitative data for wide analysis and employed experts' judgments.

From the perspective of strategic management, analyzing only performance or attractiveness levels is not enough to provide information practically useful for destination managers (Taplin, 2012). In fact, if a destination outperforms another one with reference to some aspects, it does not mean that the latter will gain competitiveness improving those aspects, whether they are not important for its target segment. This is the reason why Importance-Performance Analysis (IPA) has long been one of the preferred tools (e.g. Azzopardi \& Nash, 2013; Coghlan, 2012; Dwyer et al, 2012) for retrieving indications about how to prioritize interventions and allocate resources among different attributes of the tourism supply (Abalo et al, 2007), to increase competitiveness and efficiency. 
The traditional IPA classifies a destination's attributes in four quadrants of a bi-dimensional importance/performance plot. Conceived by Martilla and James (1977), IPA aims at identifying which product/service aspects managers should prioritize, to improve competitiveness and customer satisfaction. IPA considers overall satisfaction as a function of importance and performance of a set of attributes. It is applied in many tourism studies (e.g. Cracolici \& Nijkamp, 2009; Chi \& Qu, 2008).

\subsection{Interpretation of importance and performance measures}

Tourist satisfaction is a key factor of competitiveness, as it significantly influences the choice of destination, the purchase of more products and services, the intention to return and the likelihood of recommending the destination to others (Chen and Chen, 2010; He and Song, 2009). The American school of thought, led by Parasuraman, Zeithaml, and Berry (1985), conceives satisfaction (dissatisfaction) as the positive (negative) difference between the costumer's prior expectations and the posterior perceived performance of the product. Whereas the perceived performance-only approach (Tse \& Wilton, 1988), directly identifies satisfaction with the consumer's statement. IPA has been applied in tourism according with both conceptions of satisfaction, but recently it is mainly considered an expectation-disconfirmation model (Oliver, 2010), notwithstanding the critiques moved against this approach (Neal \& Gursoy, 2008; Fuchs \& Weiermair, 2004). In fact, there is no general consensus, in the literature about this topic, on which method is preferable. Crompton and Love (1995) claimed to have found empirical evidence that the performance-only approach is more reliable and valid, but, as pointed out by Taplin (2012b), the results of their analysis are biased by the use of absolute instead of relative stated importance.

There is no consensus on the meaning of 'importance' in the IPA literature (Dwyer et al, 2012), possibly because researchers employ different measures, that must be consistently interpreted. Importance can be measured directly (asking tourists explicit statements), statistically estimated, or obtained combining both (Hui et al, 2007; Fuchs \& Weiermair, 2004). On the one hand, the interpretation of importance statements can be difficult and not univocal, while parametric statistical estimates have a clear meaning, implied by the model, the capability of which to explain the empirical evidence can be tested. There are also confirmations that the derived method is preferable for its explanatory and predictive power (Matzler et al, 2003; Chu, 2002). On the other hand, if the performance of some attributes are highly correlated, statistical estimates are inefficient and unstable. They can also have very low predictive power if regressors are not properly chosen. Extant works regressed overall satisfaction against either attributes' performance (William \& Soutar, 2009), or performance multiplied by absolute stated importance (Crompton \& Love, 1995), or relative stated importance, also after a variable transformation (Taplin, 2012b). Taplin (2012b) compared the predictive power of importance measures derived from all the mentioned regressions and found that the latter is the best predictor of overall satisfaction. 
Regarding performance, the main interpretative problem is that tourist perceptions are variable, not only as a function of attributes quality, but also due to the differences in psychological attitude and cultural background (Alegre \& Garau, 2010). Thus, Arana and Leon (2013) pointed out that regressing satisfaction judgments on attributes performance yields estimates hardly readable in strategic terms.Moreover, destination managers can act only on the structural quality of local aspects, thus subjective and trip-related influences should be educed. This is possible, adding control variables to the equations, but not always straightforward, because of the non-linearity of the relation (Arbore \& Busacca, 2011). In fact, satisfaction statements are normally expressed on a (short) likert scale, so they are ordinal data, not linearly related to explanatory variables, that in turn can be categorical. This issue is frequently addressed through Structural Equation Models (e.g. Neal \& Gursoy, 2008), if the assumption of normality for the latent continuous variables, underlying the ordinal variables, holds. Otherwise, neglecting non linearity can bias results whether the sample size is not big enough and the responses' distribution is too asymmetric.

\subsection{Incorporating competition in IPA}

Considering competitors within IPA is crucial to provide information about potential and actual competitive advantages/disadvantages to destination managers (Mikulić \& Prebežac, 2012). Whereas competitiveness is a concept relative to many rivals acting on a broad collective scenario, traditional IPA focuses on a single destination and its original unsuitability to account for competitors has been markedly criticized (Chen, 2014; Mikulić \& Prebežac, 2012). Namely, it has been claimed that representing rivals' performances in a two-dimensional plot implies a loss of information about the relation of importance and performance within each single destination; while augmenting the dimensionality tends to produce larger matrices, instead of the synthetic and easily readable traditional graph.

For incorporating competition in IPA, or in tourist satisfaction studies, some researchers directly ask visitors comparative judgments (Taplin, 2013; Enright \& Newton, 2004), but in wide international tourist surveys it is unlikely that all the respondents visited the same places to compare. Yavas and Shemwell (2001) plotted the differences in performances (among two competitors) weighted by attribute importance against the rival's performance, losing the IPA relation within each single destination. Deng et al. (2008) plotted a hotel performance value, divided by that of its competitor, against attributes importance. But Taplin (2012) pointed out that the latter is expected to vary in different locations, so he considered the difference in importance and that in performance. All these approaches consider competitive spreads, at the cost of loosing the importance-performance relations within each single destination and, consequently, the tourism aspects' prioritization. Recently, Albayrak (2015) plotted the difference between performance and importance (gap), and that in the performances of two rivals, calling this extension of IPA Importance Performance Competitor Analysis (IPCA). This approach represents an important step forward, but requires interpreting importance as expectation, that appears inappropriate. A different approach is proposed in Taplin (2012b), considering the difference in 
performance and importance between the focal wildlife park and many rival venues, through CIPA. Plotting competitive gaps, in this advanced version of IPA, attributes are partitioned by the diagonal of the plane, gathering points of no difference in parks' competitiveness. Similarly, Moore and Taplin (2014) compared the mean performance and importance of each attribute in the focal park with the average performance and importance of the same attribute in all the considered venues.

All the previously mentioned methods allow to consider just pairs of competitors or the competitiveness gap of one destination against all its rivals, but defining all destinations' competitive level with reference to each attribute provides additional information, especially relevant on the international market, where the competition is fiercer. Other authors (e.g. Kim \& Oh, 2002, Keyt et al, 1994), consider both performance and importance of two or very few competitors, augmenting the dimensionality of the representation, but Albayrak (2015) recalls that this implies losing the global picture of the whole competitive scenario.

\subsection{Methodological critiques to IPA}

The traditional IPA plot is divided in four quadrants by two thresholds, one on each axis, classifying attributes based on their importance and performance values. Different quadrants indicate different priority and need for management actions, interventions and investments, of all the assets they include (Dwyer et al, 2012). Whence the importance to set the thresholds: switching their position, even just a bit, can change the prioritization of attributes. Thresholds can be datacentered, scale-centered or subjectively determined.

The data-centered cut-off points are the non-conditional average (Dwyer et al, 2012) or median (Shieh \& Wu, 2011) values of importance and performance. They are often chosen because of simplicity, also considering that what really matters in IPA is the prioritization of each attribute relative to the others. But Arana and Leon (2013) pointed out that data-centered thresholds are relative to the focal destination, very sensitive to extreme values, influenced by the subjective characteristics of visitors and, as such, likely to change a lot as the sample composition varies a bit. This contingency issue has been be solved, in some works, with the scale-centered thresholds, set a priori at the center of the scale according to which interviewed visitors expressed their statements (Oh, 2001). Sever (2015) highlights that this method leads to overstate the importance ratings for all the attributes and implies that barely sufficiently performing attributes are classified in the same quadrant of excellently performing ones. Moreover, the scale is fixed, while the subjective influences of tourists on their perceptions vary, as different destinations are likely to be visited by different compositions of tourist characters. Abalo et al. (2007) noted that this drawback may seriously reduce the discriminatory power of IPA and bias results. Summarizing, Azzopardi and Nash (2013) highlighted that the subjectively determined thresholds appear completely arbitrary and question the reliability of results.

An alternative approach is to give up the four quadrants and classify attributes only in 'over performing' and 'underperforming', using the diagonal of the plot, where importance equals performance, as threshold (Ziegler et al, 2012). This method, called GAP analysis, is very simple, 
robust, but loses some information, limiting the managerial usefulness of IPA. Moreover, it can be employed only when stated importance is available, and the identification of expectation with importance does not look consistent. Sever (2015) used the Receiver Operating Characteristic curve to select the threshold that maximizes the specificity and, possibly, the sensitivity of the classification. This way it is possible to realize a statistical assessment of the discriminatory and predictive power of IPA. But this method can be employed only for binary classifiers, in a GAP analysis.

\section{MCIPA innovations and interpretative framework}

MCIPA is framed in the perceived-performance theoretical approach, as it assumes that satisfaction judgments coincide with the subjective assessments of the quality of attributes. But, for increasing destination competitiveness, managers and policy makers cannot operate on the psychological and cultural attitude of the tourists, that shapes their perception of the tourism aspects' performance. Beside the destination image and brand, tourism development strategies and policies can improve the structural, objective quality of local assets. Thus, instead of employing satisfaction statements as direct measures of performance, MCIPA provides to extract estimates of such objective performance, from the statements, through very flexible generalized linear models, able to filter the psychological and cultural influences out of the perceptual construct of satisfaction.

In order to overcome the problem of how to interpret the points close to the IPA grid thresholds (Bacon, 2003) and that of the distinction between attributes with different placement within the same quadrant (Tarrant \& Smith, 2002), MCIPA relies on data-driven thresholds, not centered but set at the extremes of a zone of competitive tolerance, having a meaning similar to that of the zone of tolerance of expectation (ZOT) adopted by Chen (2014). Details about the practical procedure to set such thresholds are provided in subsection 4.3 , because they depend on the multivariate clustering of all the estimated inputs of IPA grids, described in that section.

Regarding the interpretative framework, a pivotal concept is that of strategic groups, to the best of our knowledge not already used for tourist destinations. A strategic group is composed by members pursuing similar strategies, directly competing on the same market segment and similarly affected by any intervention, policy modification and market change (Czepiel, 1992). This concept is also considered a solid foundation for a competitor-oriented expansion of market segmentation (Söllner \& Rese, 2001).For the present work, strategic groups can offer a consistent interpretative foundation to extend competitiveness analysis to many destinations simultaneously, because the description of the attributes' prioritization of a small number of strategic groups provides information on those of all their members. This makes the analysis of numerous competitors feasible, more synthetic and easily readable, allows to empirically identify competitors and portray the positioning of each area within a broad competitive scenario. In fact, the members of a strategic group show similar behavior, performance and pattern of competitive interactions (Fleisher \& Bensoussan, 2002; Pegels et al, 2000). 
The tourism literature about IPA has not already considered the target segment as a key to interpret importance measures, although Kaczyski and Crompton (2004) read the importance for residents, of destination's aspects, as the preferences of local stakeholders. Our hypothesis is that territories recording similar performance on similarly important attributes constitute a strategic group. Consistently, we assume that different compositions of importance values characterize the preferences of different tourist segments. Then, we interpret provinces competing on the same demand segment, with similar performances of core assets, as members of the same strategic group, empirically identifying direct and indirect competitors. We consider as direct rivals destinations not only addressing the same demand segment, but also showing similar performance of the similarly important attributes. As a consequence, whether two destinations address the same target segment, constituted by tourists attributing similar levels of importance to the same attributes, but the quality of the latter is different, then they are just indirect competitors.

Detecting which are the most competitive rivals, on which attribute(s), MCIPA indicates to managers and policy makers where to find best practices and inspiration for improving the problematic aspects of their own destination, similarly to what Moore \& Taplin (2014) did. MCIPA is also especially appropriate to provide operational suggestions to destination managers and policy makers, who can be responsible for multiple destinations. This is particularly true in the case of Italy, where tourism policies and many management interventions are elaborated at the NUTS 2 level (administrative region) while actual tourist destinations are better identified by provinces (NUTS 3 ). Thus, an administrative region can include either directly competing destinations or provinces with diversified offers, which should be oriented towards cooperation by regional policy makers. Whence the importance of considering the geographical and administrative structure of the competitive scenario. Namely, if a destination is contiguous to its direct competitors, regional policy interventions should be coordinated the administrative level, encourage diversification, to avoid price wars between similar offers. Conversely, whether neighboring areas target different market segments, destination management should be locally tailored at the provincial level and aim at stimulating collaboration between destinations, to realize synergies.

\section{Methodology}

\subsection{Deriving importance measures}

Deriving importance from models incorporating self-stated importance has the advantage that missing performance evaluations, with reference to some aspects, are not a problem, and possibly yields higher predictive power (see Taplin, 2012b). But stated importance can be missing, totally or in too many cases, particularly when data are collected through a survey set up for a purpose different from the competitiveness analysis (as in the application below). This is the reason why here we do not explicitly multiply satisfaction statements by stated importance, but recommend 
that, whenever importance statements are available, the choice of whether using them or not in the regression should be based on the comparison of the predictive power of the alternatives. It is also worth of note that we do not regress overall satisfaction on attributes performance (see critiques to this approach in Medina-Munoz, 2014), but on tourist satisfaction with destination aspects, as explicitly surveyed. Satisfaction judgments are normally expressed on a likert scale, so ordinal in nature and not linearly related. Whether non linearity cannot be neglected, we suggest a more generally applicable method, based on Cumulative Logit Models (CLM or ordinal logit) with parallel assumption (or proportional odds model, see: McCullagh, 1980). This model is very flexible and suitable, because it is especially parsimonious and easy to interpret, while correctly representing the ordinal structure of observations. It does not require the assumption of normally distributed residuals, nor that of homoskedasticity, so that it can be used in any case.

Assume that $\mathrm{N}$ tourists expressed satisfaction judgments on $\mathrm{R}$ attributes of a certain number of destinations $(P)$ belonging to a same nation or wider area, plus a statement of overall satisfaction. We suggest to estimate, through Maximum Likelihood, a CLM for each destination (e.g. if 100 destinations are considered, 100 CLM must be estimated):

$$
\begin{gathered}
O S_{p}=\alpha_{p}+\beta_{p}^{\prime} \mathrm{Z}_{p}+\varepsilon_{p} \\
o S_{i, p}=\ln \left(\frac{\operatorname{Pr}\left[o s_{i, p}>j \mid \alpha_{j, p}, z_{i, p}\right]}{1-\operatorname{Pr}\left[o s_{i, p}>j \mid \alpha_{j, p}, z_{i, p}\right]}\right)=\ln \left(\frac{1-\sum_{j=1}^{J} \operatorname{Pr}\left[o s_{i, p}=j \mid \alpha_{j, p}, z_{i, p}\right]}{\sum_{j=1}^{J} \operatorname{Pr}\left[o s_{i, p}=j \mid \alpha_{j, p}, z_{i, p_{i}}\right]}\right) \\
\varepsilon_{p} \sim \operatorname{Logistic}\left(\mu_{O S_{p}}, \frac{\sqrt{3}}{\pi} \sigma_{O S_{p}}\right)
\end{gathered}
$$

where $O S_{p}$ is the response vector of individual overall satisfaction statements with the $p$-th destination $(\mathrm{p}=1, \ldots, \mathrm{P})$, with mean $\mu_{O S_{p}}$ and standard deviation $\sigma_{O S_{p}} . \mathrm{Z}_{p}$ is a matrix with $\mathrm{R}$ columns ( $R$ the number of attributes), constituted by individual judgments on the $p$-th destination's attributes $\left(z_{i, p}\right) \cdot \varepsilon_{p}$ is the error component. The generic element of vector $O S_{p}, o s_{i, p}$, is the overall satisfaction statement with the $p$-th province, expressed by the $i$-th respondent $(i=1, \ldots, N)$, through the $j$ th level of the likert scale $(\mathrm{j}=1, \ldots, \mathrm{J}) . \alpha_{p}$ is a vector of $\mathrm{J}$ thresholds. $\beta_{p}^{\prime}$ is a vector of $\mathrm{R}$ relative importance coefficients to be estimated. Setting any non-significant (and eventually negative) coefficient $\beta_{r, p}$ to zero and standardizing $S C_{r, p}=\left[\exp \left(\beta_{r, p}\right)-1\right]^{*} 100$, we obtain attributes' relative importance values, comparable across destinations. These values are relative in the sense that they express the importance of the corresponding tourism aspect relative to the importance of all the other attributes for the same destination. Although they do not sum to $100 \%$, because each $S C_{r, p}$ can also exceed $100 \%$, their relative meaning is implied by the model. For example $S C_{r=F o o d, p=\text { Trento }}=120 \%$ and $S C_{r=\text { Security }, p=\text { Trento }}=40 \%$ means that increasing the tourist 
satisfaction with food in Trento by 1 point of the likert scale will increase the cumulative odd value by $120 \%$, ceteris paribus (i.e. all the satisfaction statements with all the other attributes equal). While augmenting the satisfaction with security in Trento by 1 point of the likert scale will raise the cumulative odd value by only $10 \%$, ceteris paribus. As a consequence, the probability that visitors will be more satisfied with the overall tourist experience in Trento (than they are with the current level of security in the province) will augment three times less than in the former case, so the importance of the food is higher in relation to security. This appears consistent with the proposed interpretation of importance measures as preferences characterizing the target segment. In the example, the target segment of the destination prefers culinay experiences, so the province competes on the market segment of food lovers.

These measures of importance are comparable across destinations because the satisfaction statements $z_{i, p}$ are expressed on the same scale for all the destinations, the cumulative logit transformation $\ln \left(\frac{\operatorname{Pr}\left[o s_{i, p}>j \mid \alpha_{j, p}, z_{i, p}\right]}{1-\operatorname{Pr}\left[o s_{i, p}>j \mid \alpha_{j, p}, z_{i, p_{i}}\right]}\right)$ is the same for all the CLMs, one for each province, the estimation and standardization of coefficient is the same for all the destinations. As a consequence, for example $S C_{r=\text { Environment }, p=\text { Trento }}=120 \%$ and $S C_{r=\text { Environment, } p=\text { Milan }}=30 \%$ means that environment in Milan is four times less important than in Trento, because the probability that visitors will be more satisfied with the overall tourist experience in Trento, augmenting the tourist satisfaction with environment by 1 point of the likert scale, will be four times higher than in Milan.

If directly asked in the survey, each respondent can interpret the concept of attributes' importance differently. For example, if a tourist says that food is more important than shopping, he could mean that he is willing to pay more for food than for buying other goods, or that he cares more about eating healthy than about purchasing branded products, or that in general he prefers eating than going shopping. In such cases it is questionable whether increasing the quality of food in the destination would make him more satisfied with the overall tourism experience. Conversely, the meaning of $S C_{r, p}$ measures is univocal, there is only one way to read them, because it does not depend on visitors' subjective interpretation, but on the functional form of the CLM, that is questionable but transparent.

\subsection{Deriving performance measures}

In order to take into account the critiques to the confusion between performance and satisfaction often found in IPA (Tonge \& Moore, 2007), we consider satisfaction as perceived performance, determined by both psychological attitudes and objective quality. Consequently, a feasible approach to estimate objective performance, is to model satisfaction with each destination's aspect as a function of trip and individual related variables, and the (unknown) structural quality of the attribute within each destination. Moreover, it should be considered that tourist satisfaction in the visited destination depends also on the quality of factors managed at a higher level (e.g. regional or national). This 'national' effect on local attributes performances can be estimated adding a constant term for each attribute. When employing data from surveys realized 
in different years, the inclusion of a trend $g(t)$ is advisable, to capture the dynamic of the 'national' effect. Different functional forms could be specified; in the absence of theoretical indications, the appropriate form can be empirically identified, using information criteria.

The suggested model for deriving objective performance measures from satisfaction statements takes the following form:

$$
\begin{gathered}
Y_{r}=\alpha_{r}+g(t)_{r}+\delta_{r}^{\prime} X+q_{r} P+\varepsilon_{r} \\
y_{i, r}=\ln \left(\frac{\operatorname{Pr}\left[s_{i, r}>j \mid \alpha_{r}, T, X, P\right]}{1-\operatorname{Pr}\left[s_{i, r}>j \mid \alpha_{r}, T, X, P\right]}\right)=\ln \left(\frac{1-\sum_{j=1}^{J} \operatorname{Pr}\left[s_{i, r}=j \mid \alpha_{r}, T, X, P\right]}{\sum_{j=1}^{J} \operatorname{Pr}\left[s_{i, r}=j \mid \alpha_{r}, T, X, P\right]}\right) \\
\varepsilon_{r} \sim \operatorname{Logistic}\left(\mu_{Y_{r}}, \frac{\sqrt{3}}{\pi} \sigma_{Y_{r}}\right)
\end{gathered}
$$

where $Y_{r}$, with mean $\mu_{Y_{r}}$ and standard deviation $\sigma_{Y_{r}}$, is the vector containing the $y_{i, r}$ elements, i.e. the cumulative logit transformation of $s_{i, r}$, the satisfaction statement, on the $r$-th attribute, expressed by the $i$-th respondent. $\alpha_{r}$ is a vector of $\mathrm{R}$ thresholds, representing the reference levels of 'national' quality for the $r$-th attribute. $\delta_{r}^{\prime}$ is the effect of subjective and trip-related variables $X$. $P_{i}$ is a dummy variable equal to 1 if the destination of the $i$-th respondent is the $p$-th province, 0 otherwise (fixed effects). $P$ is the matrix obtained binding $P_{i}$ for all the respondents. $q_{r}^{\prime}$ is the vector of 'filtered' attribute's quality measures, to be estimated. $\varepsilon_{r}$ is the vector of error terms. The model should be estimated through Maximum Likelihood, on the whole sample.

This approach responds to the critiques of Arana and Leon (2013): filtering out the subjective component of tourists perceptions, it allows to isolate the objective performance of local attributes. Thus, if the value of the coefficient in vector $q_{r}^{\prime}$ for a destination is positive and higher than that for another one, then, ceteris paribus (equal socio-demographic and trip-related characteristics), it is more likely that a tourist, visiting the corresponding province, will be more satisfied with the $r$-th attribute, than if he visited the other province. Therefore, standardized coefficients can be straightforwardly interpreted in terms of relative quality of local attributes (relative to other provinces, in the strategic meaning). It is worth noting that MCIPA also answers the critique moved by Azzopardi \& Nash (2013), as the scale of performance measures is the same of that of importance. Furthermore, estimating $\alpha_{r}$ avoids the bias that may affect traditional direct comparisons of stated performances, due to the tendency of visitors to respond differently to different attributes (Moore and Taplin, 2014). 
When the subjective and trip-related variables are categorical, it can happen that, if directly included in the right-hand side of the equation as dummy variables, they cause identification and multicollinearity problems. Any case, they drastically reduce the model's degrees of freedom, so the efficiency of estimates and the power of tests (Lokan \& Mendes, 2006). This problem can be addressed through techniques for dimensional reduction, for instance the Multiple Correspondence Analysis (MCA, see: Greenacre, 1984). The aim of MCA is retrieving a smaller number of continuous factors, accounting for nearly all the variability of original variables. MCA is conceived for more than two categorical variables and can be applied without any assumption or pre-condition, in any case. In fact, contrarily to chi-square analysis, MCA does not require each expected frequency to be at least 5 (Akturk et al. 2007); contrarily to Fisher's exact test, ratio test and G-statistics, it allows for expected frequencies of zero (Başpünar \& Mendeş, 2000). It should be noted that there could be a dependence relation between the continuous variables obtained through MCA and the destination (i.e. visitors of each destination share homogeneous subjective and situational characteristics), making estimates inefficient. So we suggest to always run a test for biserial correlation (see: Corder \& Foreman, 2014) to verify the null hypothesis of independence between destinations and subjective and trip-related variables. If it holds, then the factors, output of MCA, can replace the original binary variables. The corresponding coefficients $\delta_{r}^{\prime}$ must be interpreted very carefully, based on the categories appearing to the extremes of the axes. However, in the context of IPA, the aim is just to filter out the subjective component of perceived performance, thus the meaning of these coefficients can be neglected.

\subsection{Clustering techniques for a Multivariate CIPA}

The traditional IPA plot considers only one destination, or couple of rivals, at a time (in this sense we call it 'bivariate'), while wide competitive scenarios, composed by many destinations, require to take simultaneously into account a large number of competitors. To manage such a setting, we propose the MCIPA approach, where all the importance-performance relations, for all the observed destinations, are unitarily considered, compared and portrayed - although with the help of a caption highlighting competitive advantages, disadvantages and priority attributes of each strategic group. Using importance and performance measures as inputs for clustering, allows to detect strategic groups of destinations, characterized by similar positioning, strengthens and weaknesses, contending for the same target segment. In fact - as the members of a strategic group are defined by analogous performances and importance of the destinations' attributes their IPA plots would be nearly equal and very different from those of other strategic groups.

Thus, we use the importance and performance measures for each attribute as the input data for each destination to do the clustering of destinations into groups. In fact, the third phase of MCIPA relies on a multi-stage unsupervised agglomerative hierarchical algorithm, BIRCH (Zhang et al, 1997), in order to determine the number (K) and composition of strategic groups. This method is chosen because it allows pair-wise multi-step clustering, it does not require the importance and performance measures to be independent and it is least sensitive to the order of 
data input. At each clustering stage, the two R-dimensional vectors of importance and performance (the information contained in a traditional IPA grid) of one destination at a time are input. Clusters are obtained minimizing the difference of the IPA values within each group and maximizing that between groups. Thus, the resulting clusters synthesize many IPA grids.

The last step of MCIPA consists in characterizing each strategic group's positioning. Thanks to the clustering, instead of performing one fourfold classification of attributes for each of the many considered destinations, a much smaller number of classifications $(K<<)$ is required. In fact, one attributes' prioritization for each group is sufficient. It holds for all the cluster's members, because, by construction, the group is constituted by destinations where similar priority should be given to the same attributes. This dimensional reduction of the problem offers a strategically meaningful advantage in terms of interpretation, synthesis and simplification. This is necessary to make the suggested analysis easily readable by policy makers. In detail: first, we compute the mean importance and performance of each attribute within each cluster (by construction the deviations of importance and performance measures of the group members from the group mean are minimal). Then, the means between groups are compared by attribute and ranked.

The problem of setting the thresholds discriminating highly important/performing and scarcely important/performing attributes is addressed based on the inter-groups comparison. Clusters with top ranked means include destinations in which the corresponding attribute is highly important. Those with bottom ranked means are composed by areas where that aspect is scarcely important. The same holds for performance. How many means (groups) to be considered top or bottom ranked depends on the difference between the $K$ average values. If, for a certain attribute, the means of groups are concentrated around a same value, then the attribute, in those destinations, is not highly nor scarcely important (or performing). Thus, it does not make the difference in the actual competitive scenario, so destination managers and policy makers can neglect it. Aspects of this kind fall in a zone of competitive tolerance.

The main advantage of this procedure, compared to extant IPA versions, is that the resulting priority-based classification of attributes depends on a much larger sample (visitors of all the considered destinations, instead of a single one), so it is more stable and reliable. Moreover, MCIPA addresses the critiques concerning the relative structure of IPA (Sever, 2015), which is problematic as long as the relativity concerns the importance and performance of an aspect, relative to those of other attributes of the same destination, but becomes strategically meaningful if referred to the performance and importance of a certain asset of a destination, compared to those of the same attribute in other areas.

\subsection{Limitations}

The proposed approach has some practical and theoretical limitations. First, MCIPA is not as easily executable as the extant versions of IPA, because it requires familiarity with specialized softwares (e.g. SPSS, STATA, R, SAS ) having methods for categorical data analysis already implemented.. Moreover, the reading of CLM coefficients is not as straightforward as that of OLS parameters, although we tried to explain it clearly in this section. Furthermore, some knowledge of the 
terminology specific to strategic management is necessary to understand the output of the analysis.

With reference to the methodological aspects, deriving importance measures statistically entails the problems typical of regression models. First, the obtained ranking of attributes by importance may not coincide with the 'actual' one, as derived importance is determined by both the satisfaction assessments and the chosen functional form for the regression. Furthermore, if the satisfaction statements with some attributes are highly correlated, then the model suffers from multicollinearity, making importance measures largely instable. Moreover, whether local aspects actually impacting the overall tourist satisfaction are not considered, the estimated importance measures are affected by the omitted variable bias and their predictive power is low.

Omitted variables bias can also emerge when estimating attributes' objective performance. Conversely, a dimensional reduction is often necessary, implying a loss of information, as just a part of the variability of inputs is preserved in the outputs. Further methodological complexity can arise in case the relationships between each level of the dependent variable and the regressors cannot be represented by parallel lines. This circumstance violates the assumption that odds are proportional

Regarding the BIRCH clustering algorithm, the absence of assumptions and constraints can yield either many groups composed by too few destinations, in case the considered competitors are very different, or just one or two clusters including a too high number of members, if all destinations are very similar. In both situations MCIPA is not as worthwhile as it is in conditions of not-extreme homogeneity or heterogeneity of rivals.

Furthermore, the procedure we suggest for setting thresholds separating highly from scarcely important/performing attributes is very sensitive to both the number of considered tourism aspects and that of found strategic groups. Finally, the output of MCIPA focuses on the differences in attributes' prioritization between strategic groups, but does not detail the difference in competitiveness within groups. This drawback could be serious, as the competition within strategic groups is expected to be fiercer than between clusters. Although the first two steps of MCIPA provide the information necessary to fill this gap, the need for a synthetic output lead to neglect it, or better to exploit it for further analysis.

\section{An application to Italy}

Given the extraordinary potentialities of Italian destinations, boosting the growth of the tourism industry should be a priority for administrators and policy makers. They should develop effective destination management strategies, based on information about individual positioning, taking into account local weaknesses and strengths. A possible way to bring a substantial informative contribution to destination managers and policy makers, regarding the most dynamic market (the inbound tourism), is applying MCIPA to international tourists' satisfaction statements. However, as this section is just for illustrative purposes, we provide just a brief discussion of the results. 


\subsection{Data}

Tourist satisfaction judgments, socio-demographic and trip-related variables are retrieved from the survey on international tourism, realized since 1997 by the Italian Exchange Office and since 2008 by Central Bank of Italy, through about 145,000 yearly face-to-face interviews at 82 border points. The original purpose of the survey is to compute the tourism spending, for calculating the national balance of trade. With reference to the $R=9$ satisfaction statements, respondents are required to evaluate, on a scale ranging from $1={ }^{\prime}$ very bad' to $10=$ 'excellent':

- the hospitality and friendliness of local people,

- the artistic endowment of the destination,

- its landscape and natural environment,

- the accommodation structures,

- food and cuisine,

- the price level,

- the quality and variety of goods in shops,

- tourist information,

- security.

Tourists are also asked for an overall evaluation of their tourism experience. We limit the analysis to respondents who stayed in hotel structures, because they represent the macro-segment with the highest average daily expenditure. The final dataset is composed by $N=1,429,230$ observations, collected from 1997 to 2013, relative to $P=106$ Italian provinces.

We consider also trip-related variables (average daily expenditure at destination, number of nights spent in the destination province, vehicle of travel, purpose of the journey, holiday/nonholiday period), socio-demographic variables (age of the interviewed, sex, origin continent, professional condition) and a linear trend. Except for expenditure, nights and trend, all the listed variables are coded as binary, thus we use MCA to reduce their dimension. We obtain 7 continuous factors synthesizing the 32 original dummy variables.

\subsection{Results}

In the first two steps of the MCIPA methodology we set to zero all the estimated coefficients with a P-value higher than $10 \%$. We chose this threshold, instead of the usual $5 \%$, because it is a satisfying compromise between estimates significance and number of non-null measures. Running $\mathrm{BIRCH}, \mathrm{K}=8$ strategic groups are detected. Results are very stable when changing the number and the input order of provinces. As Italian destinations are particularly heterogeneous, we find many clusters composed by less than 3 destinations, while we wanted a simplified and compact output. Thus, we ran a K-mean (K=8) clustering algorithm (Hartigan \& Wong, 1979), to aggregate all the provinces in the found strategic groups. The K-mean output is perfectly consistent with the $\mathrm{BIRCH}$ one. Finally, strategic groups are represented with different colors on a map, in Figure 1. Group 0 includes the 6 least visited provinces, excluded from the cluster analysis and used as baseline in the models for performances. 
The table-caption constitutes an integral part of MCIPA output, because it characterizes the positioning of each strategic group (set of provinces with the same color on the map). It synthesizes 100 traditional IPA plots, or rather $\left(\begin{array}{c}100 \\ 2\end{array}\right)=4950$ IPCA grids (all the possible pairwise comparisons of the 100 provinces' positioning), as we compare importance and performance of destinations that are both direct competitors for the members of their own group (other provinces with the same color on the map) and all rivals in a broad meaning. In fact the choice of the destination country usually precedes that of the precise area (see: Eymann, 1995)."

At a first glance it appears that Italian provinces can find direct competitors both in the neighborhood and at a wide distance. This evidence has managerial and policy implications.

Figure 1. Map of clusters.

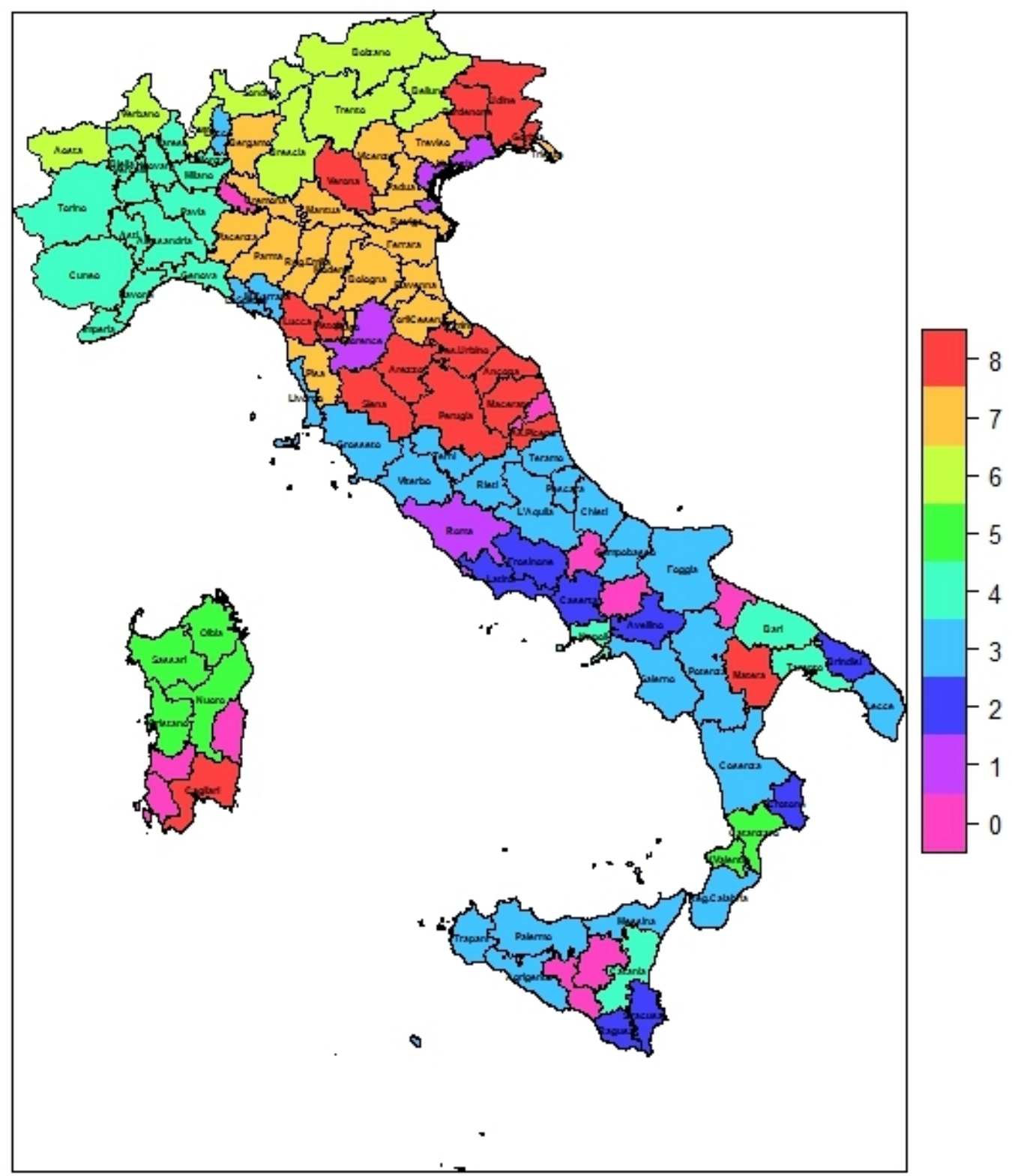


Table 1. MCIPA Caption:

\begin{tabular}{|c|c|c|c|c|}
\hline $\begin{array}{l}\text { MCIPA Strategic } \\
\text { Group }\end{array}$ & $\begin{array}{l}\text { 1: Rome, Venice, } \\
\text { Florence }\end{array}$ & $\begin{array}{l}\text { 2: Destinations of historical } \\
\text { and religious Interest }\end{array}$ & $\begin{array}{l}\text { 3: Southern destinations with } \\
\text { greatly varied territories }\end{array}$ & $\begin{array}{c}\text { 4: Industrial, } \\
\text { business, provinces }\end{array}$ \\
\hline $\begin{array}{l}\text { Low Priority } \\
\text { (low performance and low importance) }\end{array}$ & Prices & Information & Information & Environment \\
\hline $\begin{array}{l}\text { Concentrate Here } \\
\text { (low performance and high importance) }\end{array}$ & Hotels & Shopping & Shopping & Security \\
\hline $\begin{array}{l}\text { Possible Overkill } \\
\text { (high performance and low importance) }\end{array}$ & Shopping & Prices & Environment & / \\
\hline $\begin{array}{l}\text { Keep up the good work } \\
\text { (high performance and high importance) }\end{array}$ & Art & I & Food & Food, Information \\
\hline
\end{tabular}

\begin{tabular}{|c|c|c|c|c|}
\hline $\begin{array}{l}\text { MCIPA Strategic } \\
\text { Group }\end{array}$ & $\begin{array}{l}\text { 5: Naturalistic } \\
\text { destinations }\end{array}$ & 6: Alpine areas & $\begin{array}{l}\text { 7: Destinations services and } \\
\text { facilities-intensive }\end{array}$ & $\begin{array}{l}\text { 8: Worldwide } \\
\text { renown small cities }\end{array}$ \\
\hline $\begin{array}{l}\text { Low Priority } \\
\text { (low performance and low importance) } \\
\text { Concentrate Here } \\
\text { (low performance and high importance) } \\
\text { Possible Overkill } \\
\text { (high performance and low importance) } \\
\text { Keep up the good work } \\
\text { (high performance and high importance) }\end{array}$ & $\begin{array}{l}\text { Art, Food } \\
\text { Shopping } \\
\text { Hotels } \\
\text { Environment }\end{array}$ & $\begin{array}{c}\text { / } \\
\text { Security } \\
\text { Hotels } \\
\text { Information, Environment }\end{array}$ & $\begin{array}{c}\text { Hotels } \\
\text { Shopping }\end{array}$ & $\begin{array}{c}/ \\
/ \\
\text { Environment } \\
\text { Hotels, Art }\end{array}$ \\
\hline
\end{tabular}

The columns headers of the table-caption report a synthetic description of the provinces constituting the corresponding strategic group, along with the number that denotes the group and its distinctive color on the map. For example, group 8 is formed by all the provinces colored in red on the map, that are worldwide renown small cities, and the characterization of their positioning lies in the eighth column of the caption. Each caption's row represents a quadrant of the traditional IPA grid: the Low Priority row contains the names of the attributes with low performance and low importance (not highly performing nor important for tourist satisfaction); Concentrate Here row includes those with low performance and high importance; Possible Overkill row shows those with high performance and low importance; Keep up the good work row carries those with high performance and high importance. Since the clustering procedure groups provinces with the most possible similar importance-performance values and relations together, the tourism aspects reported in each row for the corresponding strategic group, would appear in the same quadrant of the individual IPA grid of all the single members of the same group. Caption's cells are empty when the destinations belonging to the corresponding strategic group would display a void quadrant in the traditional IPA representation, with reference to the corresponding level of priority (e.g. group 4 presents no possible overkill). This can be due either to the fact that many attributes, in the group members, fall in a zone of competitive tolerance (aspects irrelevant for the competition with direct competitors), or to the eventuality that all their assets are located in the other quadrants. For instance, group 1 is composed by the worldwide most known Italian destinations. Here prices appear high (low performance in this case means low affordability), but they are not important for tourists, suggesting that the target segment of this group is characterized by a low price elasticity. Art and shopping in Venice, Rome and Florence are very high in quality, but shopping is not of interest for visitors, choosing these destinations for their unique art endowment. Policy makers and managers of these provinces should focus on stimulating the improvement of accommodation structures, neglecting shops, as the low quality of hotels threatens tourist satisfaction. 
On the contrary, hotels represent a possible overkill for alpine areas, members of group 6 . Here the quality of information and environment is very high, like the importance of these aspects for tourists, as expected, considering that these destinations are renowned for winter sports and hikes. The nature itself of these activities, offered by this strategic group, could explain the need to focus resources and intervention on security.

Considering that decision-makers act at the administrative regional level, to which either homogeneous or heterogeneous provinces pertain, it is worth noting that the regions: Abruzzo, Emilia Romagna, Marche and Trentino Alto Adige, are composed by destinations that compete directly with the other provinces of the same administrative area. Here, from the perspective of strategic marketing planning and brand management, the policy makers should be aware that they lead a strategic group where the same interventions will benefit the whole pertaining area. Whereas the geographical proximity of direct rivals is likely to make the competition fiercer, so administrators should pay attention to avoid market cannibalization, as tourists seeking the same tourism experiences and targeting that geographic area are contended by members of the same region.

On the opposite, regions like Lombardia, Toscana and Veneto include destinations with different positioning. Here the decision-making process should be led at a level different than the current one. Policy makers should be aware that direct rivals of their provinces belong to other administrative regions, which can also be located very far, and that they rule a territory composed by different destinations, with the potential to provide different sets of tourism experiences, sought by various market segments. Thus destination managers should develop locally tailored tourism development strategies, looking for synergies and diversifying interventions, respecting the local peculiarities.

\section{Conclusions}

The development of MCIPA was motivated by the need to perform an analysis of the competitiveness of many destinations at the same time, and simultaneously to classify the attributes of each territory based on their priority, presenting results in a synthetic fashion. In fact, measuring competitiveness, especially with reference to tourist destinations, requires the detection and consideration of many competitors. While profiling individual positioning implies taking into account the importance and performance of various destination's aspects. Extant studies on destinations' competitiveness generally either consider many rivals, or provide a precise prioritization of interventions within a single or a couple of destinations. Thus, there seems to have been a sort of trade off between measuring competitiveness and detailing each destination's strategic positioning.

The primary aim of the present paper was to partially reduce this trade off, suggesting a methodology to perform simultaneously both tasks, expanding on the IPA literature. Recently some authors proposed modified versions of IPA, permitting the comparative analysis of either a few destinations or many competitors, but yielding the positioning of only the focal one (CIPA by Taplin, 2012b). The proposed Multivariate Competition-based IPA (MCIPA) further extends CIPA 
for providing the traditional fourfold priority-based classification of attributes for all the many destinations considered. MCIPA can be applied to any survey including questions about overall satisfaction and satisfaction with core tourism attributes.

The interpretative key, making this extension possible, is the concept of strategic group, (re)propounded for the first time in the competitiveness analysis of tourist destinations. Our hypothesis is that territories recording similar performance on similarly important attributes constitute a strategic group. Consistently, we assume that different compositions of importance values characterize the preferences of different tourist segments. Then, we interpret provinces competing on the same demand segment, with similar performances of core assets, as members of the same strategic group, empirically identifying direct and indirect competitors. The output of MCIPA is a map, showing the geographic distribution of groups, and a table-caption with the fourfold priority-based classification of aspects for each group, holding for all its members. Thus, MCIPA synthesizes many CIPA grids, providing detailed information to destination managers and policy makers.

The way MCIPA leads to reaching the proposed objective can be synthetized in 4 steps. First, importance measures are estimated, regressing the overall satisfaction statement on the satisfaction judgments with destination aspects, through Cumulative Logit Models (CLM). Second, objective performance estimates for destinations' attributes are obtained through a CLM with fixed effects. Third, importance and performance levels of all the considered destinations are used to detect strategic groups. Finally, the found clusters are characterized based on the priority of their members' attributes, determined in comparison to all the competitors.

MCIPA helps coping with some methodological and interpretative problems of IPA, highlighted by the literature. In particular, with reference to the methodology, MCIPA relies on a set of statistical techniques suitable in any case, as they do not require the distributional assumptions and restrictions needed for the traditionally employed methods. Moreover, the proposed clustering technique allows to treat the dependence relation between importance and performance, pointed out by the literature. Adopting the perceived-performance only approach, MCIPA dissolves the declared confusion (Arana \& Leon, 2013) between satisfaction and attributes' performance, modeling the former as composed by the latter, plus psychological, cultural and triprelated factors. Filtering out subjective and situational influences, MCIPA retrieves, from satisfaction statements, the structural performance of attributes. Statistically deriving importance measures, MCIPA assures that they are expressed in the same scale of performance and univocally readable, as the model itself implies their meaning. Further interpretative problems are addressed through the concept of strategic group. Then, the relative structure of IPA, the problems of setting thresholds, of interpreting the attributes close to the cut-off points and of distinguishing between aspects with different locations within the same quadrant are all addressed based on competition. Some authors claimed that the disadvantage of the relativity of IPA, applied to one or a couple of destinations, consists in its self-referentiality. While the structure of MCIPA is relative to competitors so that results are stable to changes in the size of destinations set. In fact, an aspect, the performance of which is top-ranked in the inter-clusters ranking for that asset, is classified as highly performing in the destinations belonging to the corresponding strategic group. The same is done for classifying scarcely performing aspects and 
for importance measures. Assets the importance/performance of which is similar between groups fall in a zone of competitive tolerance, that destination managers and policy makers can neglect.

For illustrative purposes, we presented the results of applying MCIPA to 100 Italian destinations. 8 strategic groups are detected, some including entire administrative regions, others composed by provinces located at a relatively far distance. This configuration of the competitive scenario has important implications for destinations managers and policy makers, especially because, in Italy, destination development strategies are formulated at the level of administrative regions. The analysis highlighted that the latter can be either homogeneous or heterogeneous, in terms of the tourist experiences their constituting provinces supply.

This empirical application is affected by some practical drawbacks, mainly due to the fact that the survey, from which we retrieved the data, is not set up for the specific purpose of the present paper. Otherwise, it would have been interesting to investigate tourist satisfaction with more numerous attributes, given the huge amount of administered questionnaires. Moreover, importance judgments are not collected, so that we could not test for the predictive power of models combining estimated coefficients and stated importance. Finally, the heterogeneity of Italian provinces is so high that too many clusters including only one or two destinations resulted from $\mathrm{BIRCH}$. As a consequence of our application of the k-mean algorithm, for aggregating unique destinations to the found clusters, the variability within groups increased. Therefore, the final attributes' prioritization is not as representative of each single member of the cluster, as it would have been if Italian tourism offer was not so multifarious.

However, the lesson resulting from this MCIPA application for Italian policy makers is that they should boost 'coopetition', to increase the number of overnight stays or arrivals and favoring the intention to return. In particular, the administrators of a heterogeneous region should implement varied international promotions, appropriately targeting various demand segments, to augment its market share. But they should also promote the other provinces' supplies within each destination, so that travelers, come with a certain purpose (e.g. business), can be tempted to return in the region to live a different experience of interest (e.g. sportive). Conversely, the policy makers of homogeneous regions should rather focus on lengthening tourists stays, promoting a unique destination image of the whole region on international stages, while communicating, within each province, the ways neighborhood destinations can widen the kind of tourist experience searched by the target segment, for a deeper and unrepeatable journey.

Concluding, further empirical research on the Italian tourism destinations' diversity is needed, to help destination managers and policy makers conceiving effective regional development strategies. Above all, the competitive performance of Italian provinces within each strategic group appear to deserve a dedicate analysis. Moreover, it would be interesting to compare the performances of Italian provinces with those of foreign destinations. 


\section{References}

Abalo, J., Varela, J., Manzano, V., 2007. Importance values for importance-performance analysis: a formula for spreading out values derived from preference rankings. J. Bus. Res. 60, 115-121.

Akturk, D., Gun, S. \& Kumuk, T. (2007). Multiple Correspondence Analysis Technique Used in Analyzing the Categorical Data in Social Sciences. Journal of Applied Sciences, 7: 585-588.

Albayrak, T. (2015) Importance Performance Competitor Analysis (IPCA): A study of hospitality companies. International Journal of Hospitality Management, 48: 135-142.

Alegre, J. \& Garau, J. (2010). Tourists satisfaction and dissatisfaction. Annals of Tourism Research, 37(1): 52-73.

Arana, J. E., \& Leon, C. J. (2013). Correcting for scale perception bias in tourist satisfaction surveys. Journal of Travel Research, 52(6), 772-788.

Arbore, A. \& Busacca, B. (2011) Rejuvenating importance-performance analysis. Journal of Service Management, 22, 3, $409-429$.

Assaf, A. G., \& Josiassen, A. (2012). Identifying and Ranking the Determinants of Tourism Performance: A Global Investigation. Journal of Travel Research, 51(4): 388-399.

Azzopardi, E., \& Nash, R. (2013). A critical evaluation of importance-performance analysis. Tourism Management, 35, 222-233.

Bacon, D. R. (2003). A comparison of approaches to importance-performance analysis. International Journal of Market Research, 45(1), 55-71.

Başpünar, E. \& Mendeş, M. (2000). The usage of Correspondence Analysis technique at the contingency tables. Journal of Agricultural Science, 6: 98-106.

Beritelli, P., Bieger, T. \& Laesser, C. (2014). The new frontiers of Destination Management: applying variable geometry as a function-based approach. Journal of Travel Research, 53(4): 403-417.

Central Bank of Italy (2014). Statistiche sul Turismo Internazionale, publicly available at: https://www.bancaditalia.it/statistiche/rapp estero/turismo-int.

Chen, K. (2014). Improving importance-performance analysis: the role of the zone of tolerance and competitor performance. The case of Taiwan's hot spring hotels. Tourism Management. 40, 260-272.

Chen, C-F. \& Chen, F-S. (2010). Experience quality, perceived value, satisfaction and behavioral intentions for heritage tourists. Tourism Management, 31 (1): 29-35.

Chi, C. G.-Q. \& Qu, H. (2008). Examining the structural relationships of destination image, tourist satisfaction and destination loyalty: An integrated approach. Tourism Management, 29(4): 624636.

Chu, R. (2002). Stated-importance versus derived-importance customer satisfaction measurement. Journal of Services Marketing, 16(4): 285 - 301.

Coghlan, A. (2012). Facilitating reef tourism management through an innovative importanceperformance analysis method. Tourism Management, 33, 767-775.

Corder, G. W. \& Foreman, D. I. (2014). Nonparametric Statistics. A step-by-step approach. Second edition. New Jersey, Wiley and Sons.

Cracolici, M. F. \& Nijkamp P. (2009). The attractiveness and competitiveness of tourist destinations: A study of Southern Italian regions. Tourism Management, 30(3): 336-344.

Crompton, J. L. \& Love, L. L. (1995). The predictive validity of alternative approaches to evaluating quality of a festival. Journal of Travel Research, 34(1): 11-25.

Crouch, G. I. (2010). Destination Competitiveness: An Analysis of Determinant Attributes. Journal of Travel Research.(3): 1-19.

De Rita, G. (2015) La palude del localismo politico. Corriere della Sera|Opinioni, 11-06-2015. 
Deng, W., Kuo, Y. \& Chen, W. (2008). Revised importance-performance analysis: three-factor theory and benchmarking. Service Industries Journal, 28 (1), 37-51.

Dwyer, L. \& Kim, C. (2003): Destination Competitiveness: Determinants and Indicators. Current Issues in Tourism, 6:5, 369-414.

Dwyer, L., Knezevic Celbar, L., Edwards, D., \& Mihalic, T. (2012). Fashioning a destination tourism future: the case of Slovenia. Tourism Management, 33, 305-316.

Enright, M. J \& Newton, J. (2004). Tourism destination competitiveness: a quantitative approach. Tourism Management, 25(1): 777-788.

Eymann, A. (1995). Consumers' spatial choice behavior. Heidelberg: Physica-Verlag

Fleisher, C. \& Bensoussan, B. (2002). STRATEGIC AND COMPETITIVE ANALYSIS: Methods and Techniques for Analyzing Business Competition. Upper Saddle River, Prentice Hall.

Fuchs, M. \& Weiermair, K. (2004). Destination Benchmarking: An Indicator-System's Potential for Exploring Guest Satisfaction. Journal of Travel Research, 42(3): 212-225.

Hartigan, J. A. \& Wong, M. A. (1979). A K-means clustering algorithm. Applied Statistics 28: 100108.

He, Y. \& Song, H. (2009). A Mediation Model of Tourists' Repurchase Intentions for Packaged Tour Services. Journal of Travel Research, 47(3): 317-331.

Hui, T. K., Wan, D. \& Ho, A. (2007). Tourists' satisfaction, recommendation and revisiting Singapore. Tourism Management, 28(4): 965-975.

Kaczyski, A.T. \& Crompton, J.L. (2004). An operational tool for determining the optimum repositioning strategy for leisure service departments. Managing Leisure, 9: 127-144.

Keyt, J. C., Yavas, U. \& Riecken, G. (1994). Importance-performance analysis: a case study in restaurant positioning. International Journal of Retail Distribution Management. 22(5), 35-40.

Kim, B. \& Oh, H., 2002. An extended application of importance-performance analysis. Journal of Hospitality Leisure Marketing. 9 (3), 107-125.

Lokan, C. \& Mendes, E. (2006). Cross-company and single-company effort models using the ISBSG database: a further replicated study. ISESE 'O6 Proceedings of the 2006 ACM/IEEE international symposium on Empirical software engineering, $75-84$.

Martilla, J. A. \& James, J. C. (1977). Importance-performance analysis. Journal of Marketing, January: 77-79.

Matzler, K., Sauerwein, E. \& Heischmidt, K.A. (2003), Importance-performance analysis revisited: the role of the factor structure of customer satisfaction, The Service Industries Journal, 23(2), pp. $112-129$.

McCullagh, P. (1980). Regression Models for Ordinal Data. Journal of the Royal Statistical Society, Series B (Methodological), 42(2): 109-142.

Medina-Munoz, D. R. \& Medina-Munoz, R. D. (2014). The Attractiveness of Wellness Destinations: An Importance-Performance-Satisfaction Approach. International Journal of Tourism Research, 16: 521-533.

Mikulić, J. \& Prebežac, D. (2012). Accounting for dynamics in attribute-importance and for competitor performance to enhance reliability of BPNN-based importance-performance analysis. Expert Systems with Applications. 39 (5), 5144-5153.

Moore, S.A. and Taplin, R (2014). A benchmarking method for visitor management by national park agencies. Visitor Studies. 17(1), 107-127.

Murphy, P., Pritchard, M. P. \& Smith, B. (2000). The destination product and its impact on traveler perceptions. Tourism Management, 21(1): 43-52.

Neal, J. D. \& Gursoy, D. (2008). A Multifaceted Analysis of Tourism Satisfaction. Journal of Travel Research, 47(1): 53-62.

Oh, H. (2001). Revisiting importance-performance analysis. Tourism Management, 22, 617-627. 
Oliver, R. L. (2010). Satisfaction: A behavioral perspective on the consumer (2nd ed.). New York: M.E. Sharpe.

Parasuraman, A., Zeithaml, V. A. \& Berry, L. L. (1985). A Conceptual Model of Service Quality and Its Implications for Future Research. Journal of Marketing, 49 (fall): 41-50.

Pegels, C. C., Song, Y. I., Yang, B. (2000). Management heterogeneity, competitive interaction groups and firm performance. Strategic Management Journal, 21: 911-923.

Ritchie, B. J. R. \& Crouch, G. I. (2003). The Competitive Destination: A Sustainable Perspective. Cambridge: Cabi Publishing.

Seddighi, H. R. \& Theocharous, A. L. (2002). A model of tourism destination choice: a theoretical and empirical analysis. Tourism Management. 23, 475-487.

Sever, I. (2015). Importance-performance analysis: A valid management tool? Tourism Management. 48, 43-53.

Söllner, A. \& Rese, M. (2001). Market segmentation and the structure of competition: applicability of the strategic group concept for an improved market segmentation on industrial markets. Journal of Business Research. 51(1): 25-36.

Taplin, R.H., 2012. Competitive importance-performance analysis of an Australian wildlife park. Tourism Management. 33 (1), 29-37.

Taplin, R.H. (2012b). The value of self-stated attribute importance to overall satisfaction. Tourism Management 33: 295-304.

Taplin, R.H. (2013). The Influence of Competition on Visitor Satisfaction and Loyalty. Tourism Management. 36: 238-246.

Tarrant, A. \& Smith, E. K. (2002). The use of modified importance-performance framework to examine visitor satisfaction with attributes of outdoor recreation settings. Managing Leisure, 7 , 69-82.

Tonge, J. \& Moore, S. A. (2007). Importance-satisfaction analysis for marine-park hinterlands: a Western Australian case study. Tourism Management 28: 768-776.

Tse, D. K. \& Wilton, P. C. (1988). Models of Consumer Satisfaction Formation, an Extension. Journal of Marketing Research, 25:204-212.

Williams, P., \& Soutar, G. N. (2009). Value, satisfaction and behavioural intentions in an adventure tourism context.Annals of Tourism Research, 36(3), 413-439.

Yavas, U. \& Shemwell, D.J., (2001). Modified importance-performance analysis: an application to hospitals. International Journal of Health Care Quality Assurance. 14 (3), 104-110.

Zhang, T., Ramakrishnan, R. \& Livny, M. (1997). BIRCH: A New Data Clustering Algorithm and Its Applications. Data Mining and Knowledge Discovery, 1: 141-182.

Ziegler, J., Dearden, P. \& Rollins, R. (2012). But are tourists satisfied? Importance performance analysis of the whale shark tourism industry on Isla Holbox, Mexico. Tourism Management, 33, 692-701. 